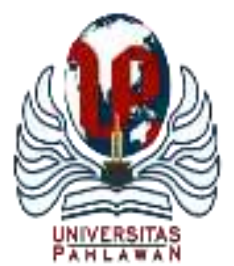

\title{
JURNALBASICEDU
}

Volume 6 Nomor 1 Tahun 2022 Halaman 1037 - 1045

Research \& Learning in Elementary Education

https://jbasic.org/index.php/basicedu

\section{Pengaruh Model Think Pair Share Terhadap Hasil Belajar Siswa Sekolah Dasar}

\author{
Laylatus Sholichah $^{1 凶}$, Ery Rahmawati ${ }^{2}$, Galuh Kartika Dewi ${ }^{3}$
}

Pendidikan Guru Sekolah Dasar, STKIP PGRI Sidoarjo, Indonesia ${ }^{1,2,3}$

E-mail: laylatus626@gmail.com ${ }^{1}$, eryrahmawati521@gmail.com² ${ }^{2}$,galuhkartika86@gmail.com ${ }^{3}$

\begin{abstract}
Abstrak
Penelitian ini bertujuan untuk mengetahui aktivitas belajar dan pengaruh model Think Pair Share terhadap hasil belajar siswa kelas IV Sekolah Dasar. Jenis penelitian ini adalah penelitian kuantitatif dengan desain Pre-test Pos-test Control Group Design. Populasi yang digunakan dalam penelitian ini adalah seluruh siswa kelas IV MINU Plus Islamiyah yang terdiri dari 37 siswa kelas IV A dan 34 siswa kelas IV B. Sampel yang digunakan yaitu 18 siswa kelas IV A sebagai kelas eksperimen dan 17 siswa kelas IV B sebagai kelas kontrol. Teknik analisis data yang diperoleh dalam penelitian ini pada aktivitas belajar melalui lembar pengamatan aktivitas siswa sedangkan hasil belajar siswa diperoleh melalui pre test dan post test. Teknik pengumpulan data pada penelitian ini meliputi observasi, tes, dan dokumentasi. Hasil penelitian ini menunjukkan aktivitas belajar siswa memperoleh persentase 92\% (sangat baik). Hasil belajar siswa pada kelas eksperimen memperoleh rata-rata nilai 90,78 sedangkan pada kelas kontrol memperoleh rata-rata nilai 77,76 serta berdasarkan hasil uji-t bahwa nilai Sig. (2-tailed) sebesar 0,000 $<0,05$ maka dapat disimpulkan bahwa terdapat perbedaan hasil belajar kelas eksperimen dan kontrol untuk nilai pre test dan post test.

Kata Kunci: Model Think Pair Share, Aktivitas Belajar, Hasil Belajar.
\end{abstract}

\begin{abstract}
This study aims to determine learning activities and the effect of the Think Pair Share model on the learning outcomes of fourth grade elementary school students. This type of research is a quantitative study with a pretest design. Post-test Control Group Design. The population used in this study were all fourth grade students of MINU Plus Islamiyah which consisted of 37 students of class IV A and 34 students of class IV B. The samples used were 18 students of class IV A as the experimental class and 17 students of class IV B as the control class. Data analysis techniques obtained in this study on learning activities through student activity observation sheets while student learning outcomes were obtained through pre-test and post-test. Data collection techniques in this study include observation, tests, and documentation. The results of this study indicate that students' learning activities get a percentage of 92\% (very good). Student learning outcomes in the experimental class obtained an average value of 90.78 while the control class obtained an average value of 77.76 and based on the results of the t-test that the value of Sig. (2-tailed) of $0.000<0.05$, it can be concluded that there are differences in the learning outcomes of the experimental and control classes for the pre-test and post-test scores.
\end{abstract}

Keywords: Think Pair Share Model, Learning Activities, Learning Outcomes.

Copyright (c) 2022 Laylatus Sholichah, Ery Rahmawati,

Galuh Kartika Dewi

$\triangle$ Corresponding author :

Email : laylatus626@gmail.com

DOI : https://doi.org/10.31004/basicedu.v6i1.2079

ISSN 2580-3735 (Media Cetak)

ISSN 2580-1147 (Media Online)

Jurnal Basicedu Vol 6 No 1 Tahun 2022 p-ISSN 2580-3735 e-ISSN 2580-1147 
1038 Pengaruh Model Think Pair Share Terhadap Hasil Belajar Siswa Sekolah Dasar - Laylatus Sholichah, Ery Rahmawati, Galuh Kartika Dewi

DOI: https://doi.org/10.31004/basicedu.v6i1.2079

\section{PENDAHULUAN}

Pendidikan adalah upaya untuk meningkatkan kualitas Kehidupan manusia dan bertujuan memanusiakan manusia (Lazwardi, 2017). Oleh sebab itu, pendidikan berfokus pada pembentukan kepribadian unggul yang berfokus pada proses kematangan kualitas berpikir, spiritual, moral dan agama. Pendidikan memiliki peranan penting dalam proses merubah tingkah laku individu tentunya harus mempunyai tujuan yang ingin dicapai (Nabila, 2021). Melalui pendidikan akan merubah cara berpikir yang lebih baik dan praktis, karena melalui pendidikan akan merubah orang-orang untuk menuju kehidupan yang lebih baik. Dalam dunia pendidikan, untuk mencapai tujuan pendidikan yang diharapkan perlu juga diperhatikan mutu pendidikan. Mutu pendidikan dapat dikatakan berhasil jika dilaksanakan secara menyeluruh dengan cara meningkatkan mutu Pendidikan (Faizah, 2019). Mutu itu sendiri dapat dilihat dari keberhasilan peserta didik dalam kegiatan pembelajaran. Hal yang penting dalam proses pembelajaran adalah menanamkan makna kegiatan belajar kepada siswa, sehingga hasil belajarnya bermanfaat untuk kehidupan mereka saat ini dan yang akan datang.

Dengan perkembangan ilmu pengetahuan dan kemajuan teknologi membawa manfaat terhadap pekerjaan manusia menjadi lebih efektif, efisien, lebih mudah, dan lebih cepat (Tari \& Hutapea, 2020). Hal tersebut berdampak terhadap pendidikan yang bertumpu pada kualitas dan kemampuan guru. Salah satu kompetensi yang harus dimiliki oleh guru pada saat ini salah satunya mampu menginspirasi belajar dan kreatifitas peserta didik serta menggunakan model pembelajaran yang sesuai dengan materi yang akan disampaikan kepada peserta didik (Giantara, 2020). Hal tersebut terkait dengan permasalahan belajar yang dihadapi siswa. Oleh karena itu diperlukan sosok guru yang memiliki kompetensi, kualifikasi, dan professionalitasnya dalam mengajar yang baik untuk menghasilkan peserta didik yang berprestasi. Menurut Dewi (2017) guru memiliki posisi strategis dalam pengembangan sumber daya manusia. Guru perlu terus memperhatikan perkembangan konsep-konsep yang berkaitan dengan profesi pendidik. Apabila guru kurang dapat menyesuaikan metode pembelajaran dengan karakteristik dan kebutuhan belajar atau guru kurang tepat dalam memilih metode pembelajaran siswa, maka dapat menyebabkan rendahnya hasil belajar siswa (Rahmawati \& Dewi, 2020).

Menurut Ramli (2015) peserta didik merupakan anak yang belum memiliki kedewasaan dan memerlukan orang lain untuk mendidiknya sehingga menjadi individu yang dewasa, memiliki jiwa spiritual, aktifitas dan kreatifitas sendiri. Peserta didik juga berhak mendapatkan pelayanan pendidikan sesuai dengan bakat, minat, dan kemampuan agar tumbuh dan berkembang dengan baik serta mempunyai kepuasan dalam menerima pelajaran yang diberikan oleh pendidiknya (Kirom, 2017). Oleh karena itu, peserta didik adalah individu yang memiliki potensi untuk berkembang melalui proses pendidikan dalam jenis pendidikan tertentu dan berusaha mengembangkan potensinya.

Kurikulum 2013 sekolah dasar melahirkan suatu mata pelajaran yang digabung menjadi satu kesatuan yang disebut pembelajaran tematik. Tematik adalah suatu konsep umum yang dapat mengumpulkan beberapa bagian menjadi satu hal. Dapat dipahami bahwa pembelajaran tematik merupakan kegiatan pembelajaran yang tidak memisahkan mata pelajaran, tetapi menggunakan tema untuk menyatukannya (Lubis, 2020). Pembelajaran tematik menuntut guru agar kreatif untuk menyelenggarakan pembelajaran yang runtut dan menemukan keterkaitan antar mata pelajaran sehingga siswa tidak merasa bahwa mata pelajaran telah berganti (Perdana \& Suswandari, 2021).

Model pembelajaran adalah kerangka konseptual yang menggambarkan prosedur sistematis dalam mengorganisasi pengalaman belajar untuk mencapai tujuan pembelajaran tertentu, dan berfungsi sebagai panduan bagi perancang pembelajaran (Trianto, 2014). Dalam dunia pendidikan terdapat model pembelajaran salah satunya adalah kooperatif. Pembelajaran kooperatif merupakan model pembelajaran yang menitikberatkan pada pemanfaatan kelompok siswa untuk bekerja sama memaksimalkan kondisi 
1039 Pengaruh Model Think Pair Share Terhadap Hasil Belajar Siswa Sekolah Dasar - Laylatus Sholichah, Ery Rahmawati, Galuh Kartika Dewi

DOI: https://doi.org/10.31004/basicedu.v6i1.2079

pembelajaran guna mencapai tujuan pembelajaran yang diharapkan. Dalam model pembelajaran kooperatif terdapat macam-macam model pembelajaran salah satunya yaitu Think Pair Share. Menurut Shoimin (2017) model pembelajaran Think Pair Share merupakan model pembelajaran kooperatif yang memberikan waktu kepada siswa untuk berpikir, merespon dan saling membantu.

Adapun langkah-langkah model Think Pair Share (Mundelsee \& Jurkowski, 2021:2) adalah sebagai berikut: (1) Berpikir: Setiap siswa memikirkan permasalahan yang diberikan secara individu dan didorong untuk mencatat (2) Berpasangan: siswa kemudian dikelompokkan menjadi pasangan-pasangan (biasanya dengan teman duduknya) untuk bertukar dan mendiskusikan ide mereka. berpasangan tidak hanya memungkinkan siswa untuk memeriksa pemikiran mereka sendiri, tetapi juga untuk mempertimbangkan pemikiran pasangan mereka tentang masalah tersebut, (3) Berbagi: Siswa membagikan ide-ide mereka yang telah terbukti dan mempresentasikan hasil diskusinya didepan siswa yang lain.

Hasil belajar adalah kemampuan yang dimiliki peserta didik setelah menerima pengalaman belajar, setelah proses pembelajaran selesai maka peserta didik mendapatkan hasil belajar (Purwasih, 2020). Sedangkan menurut Sugiarto (2020) hasil belajar adalah hasil yang diperoleh siswa setelah kegiatan belajar dan pembelajaran, serta bukti keberhasilan yang telah dicapai seseorang yang melibatkan aspek kognitif, afektif, maupun psikomotor yang dinyatakan dalam simbol, huruf, dan kalimat. Mirdanda (2018) menyatakan bahwa faktor-faktor yang mempengaruhi belajar dapat digolongkan menjadi 2 yaitu faktor intern (jasmaniah, psikologis dan kelelahan) dan faktor ekstern (keluarga, sekolah, masyarakat).

Hasil observasi yang dilakukan oleh peneliti pada tanggal 3 November 2020 dengan guru kelas IV MINU Plus Islamiyah bahwasanya dalam proses pembelajaran guru masih sering menggunakan metode pembelajaran ceramah sehingga dalam proses pembelajaran ini membuat siswa menjadi cepat bosan, kurang konsentrasi, kurangnya sosialisasi antar teman, dan siswa menjadi pasif. Dari 34 siswa yang mendapat nilai diatas KKM hanya 35.3\% dengan rata-rata nilai 66, sedangan KKM mata pelajaran tema yaitu 70. Dari ratarata nilai yang diperoleh siswa, masih banyak yang mendapat nilai dibawah KKM. Tujuan diterapkannya model pembelajaran kooperatif tipe Think Pair Share karena model pembelajaran ini mengajak siswa agar dapat mandiri, mengasah kecerdasan otak, berani berpendapat, lebih menyenangkan, siswa tidak mudah bosan, dan meningkatkan hasil belajar siswa setelah guru menerapkan model pembelajaran kooperatif tipe Think Pair Share.

Dengan memperhatikan fakta-fakta permasalahan diatas, masalah pembelajaran yang terjadi di MINU Plus Islamiyah kelas IV semester I tahun pelajaran 2020/2021 adalah pembelajaran menggunakan metode konvensional yang menyebabkan aktivitas belajar dan hasil belajar siswa masih rendah. Dengan demikian urgensi penelitian ini adalah pengaruh model Think Pair Share terhadap hasil belajar siswa kelas IV sekolah dasar.

\section{METODE PENELITIAN}

Dalam penelitian ini peneliti menggunakan jenis penelitian kuantitatif. Penelitian kuantitatif merupakan suatu penelitian yang terstruktur dan keabsahan datanya dapat diuji kebenarannya. Menurut Sugiyono (2018:14) metode penelitian kuantitatif dapat didefinisikan sebagai metode penelitian yang berlandaskan pada filsafat positivisme, digunakan untuk meneliti sampel atau populasi tertentu, teknik pengambilan sampel dilakukan secara random, pengumpulan data dilakukan dengan menggunakan instrumen penelitian, analisis data bersifat kuantitatif yang bertujuan untuk menguji hipotesis yang sudah ditetapkan.

Dalam penelitian ini peneliti menggunakan jenis penelitian kuantitatif dengan desain Pre-test Pos-test Control Group Design. Teknik pengumpulan data yang digunakan meliputi observasi, tes, dan dokumentasi. Instrumen yang digunakan dalam penelitian ini yaitu lembar validasi soal tes, lembar validasi ahli materi, soal tes, lembar pengamatan aktivitas belajar siswa. Penelitian ini dilaksanakan di MINU Plus Islamiyah. Populasi 
1040 Pengaruh Model Think Pair Share Terhadap Hasil Belajar Siswa Sekolah Dasar - Laylatus Sholichah, Ery Rahmawati, Galuh Kartika Dewi

DOI: https://doi.org/10.31004/basicedu.v6i1.2079

dalam penelitian ini yaitu seluruh siswa kelas IV MINU Plus Islamiyah yang terdiri dari 37 siswa kelas IV A dan 34 siswa kelas IV B. Sampel yang digunakan yaitu 18 siswa kelas IV A sebagai kelas eksperimen dan 17 siswa kelas IV B sebagai kelas kontrol.

Data yang digunakan untuk mengetahui aktivitas belajar dengan menggunakan lembar pengamatan aktivitas belajar siswa sedangkan hasil belajar siswa diperoleh melalui pre test dan post test. Test tersebut telah diuji coba terlebih dahulu dengan menggunakan uji validitas, reliabilitas, normalitas, homogenitas, dan uji hipotesis penelitian dengan menggunakan uji-t.

\section{HASIL DAN PEMBAHASAN PENELITIAN}

Sebelum penelitian berlangsung, peneliti melakukan validasi ahli soal tes kepada wali kelas IV dengan diperoleh data jumlah keseluruhan nilai dari item 1 sampai 12 yaitu 42. selanjutnya dihitung nilai persentase angket dengan menggunakan rumus sebagai berikut:

$$
\begin{gathered}
\text { Persentase }(P)=\frac{\text { Jumlah skor perolehan }}{\text { Jumlah skor maksimal }} \times 100 \% \\
\text { Persentase }(P)=\frac{42}{48} \times 100 \% \\
\text { Persentase }(P)=87 \%(\text { Sangat baik) }
\end{gathered}
$$

Berdasarkan hasil diatas, apabila persentase tersebut dikonversikan kedalam tabel kriteria penilaian maka dapat disimpulkan bahwa lembar validasi intrumen tes sangat baik dan layak digunakan.

Selanjutnya peneliti melakukan validasi ahli materi kepada dosen STKIP PGRI Sidoarjo dengan diperoleh jumlah keseluruhan nilai dari item 1 sampai 8 yaitu 25. selanjutnya dihitung nilai persentase angket dengan menggunakan rumus sebagai berikut:

$$
\begin{gathered}
\text { Persentase }(P)=\frac{\text { Jumlah skor perolehan }}{\text { Jumlah skor maksimal }} \times 100 \% \\
\text { Persentase }(P)=\frac{25}{32} \times 100 \% \\
\text { Persentase }(P)=78 \% \text { (Sangat baik) }
\end{gathered}
$$

Berdasarkan hasil di atas, apabila persentase tersebut dikonversikan kedalam tabel kriteria penilaian maka dapat disimpulkan bahwa lembar validasi ahli materi sangat baik dan layak digunakan.

Hasil observasi aktivitas belajar siswa pada pembelajaran tema 3 subtema 2 pembelajaran 1 dapat diperoleh hasilnya sebagai berikut:

Tabel 1. Hasil Analisis Aktivitas Siswa

\begin{tabular}{clccc}
\hline No & Nama & $\begin{array}{c}\text { Skor } \\
\text { Siswa }\end{array}$ & $\mathrm{P}(\%)$ & Keterangan \\
\hline 1 & MES & 37 & 92.50 & Sangat Baik \\
\hline 2 & ARR & 37 & 92.50 & Sangat Baik \\
\hline 3 & AAR & 40 & 100.00 & Sangat Baik \\
\hline 4 & ANMP & 36 & 90.00 & Sangat Baik \\
\hline 5 & AR & 39 & 97.50 & Sangat Baik \\
\hline 6 & CHZ & 38 & 95.00 & Sangat Baik \\
\hline 7 & FWF & 38 & 95.00 & Sangat Baik \\
\hline 8 & FSI & 36 & 90.00 & Sangat Baik \\
\hline 9 & FTRF & 39 & 97.50 & Sangat Baik \\
\hline 10 & GJA & 36 & 90.00 & Sangat Baik \\
\hline 11 & HAS & 37 & 92.50 & Sangat Baik \\
\hline
\end{tabular}


1041 Pengaruh Model Think Pair Share Terhadap Hasil Belajar Siswa Sekolah Dasar - Laylatus Sholichah, Ery Rahmawati, Galuh Kartika Dewi

DOI: https://doi.org/10.31004/basicedu.v6i1.2079

\begin{tabular}{lllll}
\hline 12 & JSN & 35 & 87.50 & Sangat Baik \\
\hline 13 & JTA & 34 & 85.00 & Sangat Baik \\
\hline 14 & KD & 34 & 85.00 & Sangat Baik \\
\hline 15 & KFN & 35 & 87.50 & Sangat Baik \\
\hline 16 & KAK & 35 & 87.50 & Sangat Baik \\
\hline 17 & MRP & 39 & 97.50 & Sangat Baik \\
\hline 18 & MDBA & 38 & 95.00 & Sangat Baik \\
\hline
\end{tabular}

Dari hasil perhitungan data diatas jumlah keseluruhan nilai pertanyaan dari aspek yang dinilai memperoleh total skor 663 dengan persentase 92\%. Berdasarkan hasil diatas, apabila persentase tersebut dikonversikan kedalam tabel kriteria penilaian dapat disimpulkan bahwa aktivitas siswa setelah diterapkannya model Think Pair Share sangat baik.

Lembar soal tes yang digunakan pada penelitian hasil belajar yaitu harus memenuhi beberapa kriteria diantaranya adalah validitas dan reliabilitas. Adapun kriteria kevalidan setiap soal pada penilaian tes sebagai berikut:

Tabel 2. Output Hasil Uji Validitas

\begin{tabular}{lccc}
\hline No Soal & $\begin{array}{c}\text { Pearson } \\
\text { Correlation }\end{array}$ & Nilai Sig. & Kesimpulan \\
\hline $1 \mathrm{a}$ & $0.329^{* *}$ & 0.005 & VALID \\
\hline $\mathrm{2a}$ & $0.380^{* *}$ & 0.001 & VALID \\
\hline $\mathrm{3a}$ & $0.361^{* *}$ & 0.002 & VALID \\
\hline $4 \mathrm{a}$ & $0.321^{* *}$ & 0.007 & VALID \\
\hline $5 \mathrm{a}$ & $0.479^{* *}$ & 0 & VALID \\
\hline $6 \mathrm{a}$ & $0.301^{*}$ & 0.011 & VALID \\
\hline $\mathrm{7a}$ & $0.514^{* *}$ & 0 & VALID \\
\hline $8 \mathrm{a}$ & $0.374^{* *}$ & 0.001 & VALID \\
\hline $9 \mathrm{a}$ & $0.317^{* *}$ & 0.007 & VALID \\
\hline $10 \mathrm{a}$ & $0.380^{* *}$ & 0.001 & VALID \\
\hline $1 \mathrm{~b}$ & $0.331^{* *}$ & 0.005 & VALID \\
\hline $\mathrm{2b}$ & $0.409^{* *}$ & 0 & VALID \\
\hline $3 \mathrm{~b}$ & $0.355^{* *}$ & 0.003 & VALID \\
\hline $4 \mathrm{~b}$ & $0.302^{*}$ & 0.011 & VALID \\
\hline $5 \mathrm{~b}$ & $0.250^{*}$ & 0.037 & VALID \\
\hline $1 \mathrm{c}$ & $0.339^{* *}$ & 0.004 & VALID \\
\hline $\mathrm{cc}$ & $0.269^{*}$ & 0.024 & VALID \\
\hline $3 \mathrm{c}$ & $0.279^{*}$ & 0.019 & VALID \\
\hline $4 \mathrm{c}$ & $0.246^{*}$ & 0.04 & VALID \\
\hline $5 \mathrm{c}$ & $0.315^{* *}$ & 0.008 & VALID \\
\hline & & &
\end{tabular}

Berdasarkan hasil uji validitas dengan menggunakan bantuan aplikasi SPSS 24.0 diperoleh hasil jika Sig < 0,05 maka instrumen soal dinyatakan valid.

Uji reliabilitas digunakan untuk mengukur soal tes yang akan digunakan dalam penelitian. Peneliti menggunakan metode Alpha Cronbach untuk uji reliabilitas soal tes dengan menggunakan bantuak aplikasi SPSS 24.0.

Tabel 3. Output Uji Reliabilitas

\begin{tabular}{cc|}
\hline \multicolumn{2}{c|}{ Reliability Statistics } \\
\hline Cronbach's Alpha & N of Items \\
\hline 0.606 & 20 \\
\hline
\end{tabular}


1042 Pengaruh Model Think Pair Share Terhadap Hasil Belajar Siswa Sekolah Dasar - Laylatus Sholichah, Ery Rahmawati, Galuh Kartika Dewi

DOI: https://doi.org/10.31004/basicedu.v6i1.2079

Berdasarkan data diatas menunjukkan bahwa nilai Cronbach's Alpha 0,606 > 0,6. Dengan demikian dapat disimpulkan bahwa instrumen penelitian yang diuji yaitu reliabel.

Untuk menguji normalitas data yang diperoleh dari nilai pre test dan post test pada kelas eksperimen maupun kelas kontrol yaitu:

Tabel 4. Output Uji Normalitas

\begin{tabular}{|c|c|c|c|c|c|c|c|}
\hline \multicolumn{8}{|c|}{ Tests of Normality } \\
\hline & \multirow[b]{2}{*}{ Tes } & \multicolumn{3}{|c|}{ Kolmogorov-Smirnov a } & \multicolumn{3}{|c|}{ Shapiro-Wilk } \\
\hline & & Statistic & df & Sig. & Statistic & $\mathrm{df}$ & Sig. \\
\hline \multirow{4}{*}{$\begin{array}{l}\text { Hasil Belajar } \\
\text { Siswa }\end{array}$} & Pre-Test Eksperimen & . 149 & 18 & $.200^{*}$ & .913 & 18 & .097 \\
\hline & $\begin{array}{l}\text { Post-Test } \\
\text { Eksperimen }\end{array}$ & .185 & 18 & .104 & .928 & 18 & .177 \\
\hline & Pre-Test Kontrol & .110 & 17 & $.200^{\prime}$ & .970 & 17 & .814 \\
\hline & Post-Test Kontrol & .177 & 17 & .160 & .917 & 17 & .133 \\
\hline
\end{tabular}

*. This is a lower bound of the true significance.

a. Lilliefors Significance Correction

Berdasarkan perolehan data diatas, dapat disimpulkan bahwa data dari kelas eksperimen dan kelas kontrol adalah sig > 0,05. Hal ini berarti data penelitian berdistribusi normal. Karena data berdistribusi normal, maka dapat dilakukan uji statistik parametrik yaitu uji Paired Sample T-Test dan Independent Sample T-Test.

Uji homogenitas dilakukan untuk mengetahui data yang diperoleh dari dua kelompok memiliki varian yang homogen atau tidak. Analisis varian dapat digunakan apabila varian data tersebut homogen. Adapun kriteria uji homogenitas adalah sebagai berikut:

Tabel 5. Output Uji Homogenitas

\begin{tabular}{|c|c|c|c|}
\hline Hasil Belajar Siswa & & & \\
\hline Levene Statistic & df1 & df 2 & Sig. \\
\hline .387 & 1 & 33 & .538 \\
\hline
\end{tabular}

Berdasarkan output di atas diketahui nilai signifikansi (Sig.) 0,538 > 0,05. Dapat disimpulkan bahwa data penelitian yang digunakan adalah homogen. Karena data penelitian homogen, maka dapat dilanjutkan untuk uji statistik parametrik yaitu uji Independent Sample t-Test.

Uji hipotesis yang digunakan pada penelitian ini yaitu menggunakan uji paired sampel T-test. Uji ini merupakan uji parametrik yang digunakan pada kedua kelompok data yang berpasangan.

Tabel 6. Hasil Uji Paired Sampel T-test

Paired Samples Test

Paired Differences

\begin{tabular}{|c|c|c|c|c|c|c|c|c|c|}
\hline & \multicolumn{5}{|c|}{ Paired Differences } & \multirow[b]{3}{*}{$\mathrm{t}$} & \multirow[b]{3}{*}{ df } & \multirow{3}{*}{$\begin{array}{l}\text { Sig. (2- } \\
\text { tailed) }\end{array}$} \\
\hline & & \multirow[b]{2}{*}{ Mean } & \multirow{2}{*}{$\begin{array}{c}\text { Std. } \\
\text { Deviation }\end{array}$} & \multirow{2}{*}{$\begin{array}{l}\text { Std. Error } \\
\text { Mean }\end{array}$} & \multicolumn{2}{|c|}{$\begin{array}{l}95 \% \text { Confidence } \\
\text { Interval of the } \\
\text { Difference }\end{array}$} & & & \\
\hline & & & & & Lower & Upper & & & \\
\hline Pair & Pre-test Kelas & - & 5.941 & 1.400 & -24.288 & -18.379 & - & 17 & .000 \\
\hline 1 & $\begin{array}{l}\text { Eksperimen - } \\
\text { Post-test Kelas } \\
\text { Eksperimen }\end{array}$ & 21.333 & & & & & 15.235 & & \\
\hline
\end{tabular}


1043 Pengaruh Model Think Pair Share Terhadap Hasil Belajar Siswa Sekolah Dasar - Laylatus Sholichah, Ery Rahmawati, Galuh Kartika Dewi

DOI: https://doi.org/10.31004/basicedu.v6i1.2079

\begin{tabular}{ll|l|r|r|r|r|r|r}
\hline $\begin{array}{l}\text { Pair } \\
2\end{array}$ & $\begin{array}{l}\text { Pre-test Kelas } \\
\text { Kontrol - Post-test 14.588 } \\
\text { Kelas Kontrol }\end{array}$ & 4.638 & 1.125 & -16.973 & -12.204 & - & 16 & .000 \\
\hline
\end{tabular}

Diketahui bahwa nilai Sig. (2-tailed) sebesar 0,000 $<0,05$ maka dapat disimpulkan bahwa terdapat perbedaan yang nyata hasil belajar kelas eksperimen dan kelas kontrol untuk nilai pre test dan post test sehingga dapat disimpulkan ada pengaruh penggunaan model Think Pair Share maupun metode konvensional terhadap hasil belajar kelas eksperimen dan kelas kontrol.

Pada penelitian ini juga menggunakan uji independent sampel t-test. Uji ini merupakan uji parametrik yang digunakan pada kedua kelompok data yang tidak berpasangan. Prasyarat dari uji ini yaitu data berdistribusi normal dan homogen. Berikut hasil uji independent sampel t-test:

Tabel 7. Output Independent Sampel T-Test

\section{Independent Samples Test}

\begin{tabular}{|c|c|c|c|c|c|c|c|c|c|c|}
\hline & & $\begin{array}{r}\text { Levene's } \\
\text { Equal } \\
\text { Varia } \\
\end{array}$ & $\begin{array}{l}\text { est for } \\
y \text { of } \\
\text { ces }\end{array}$ & & & $\mathrm{t}$-test & for Equal & lity of Me & & \\
\hline & & & & & & Sig. (2- & $\begin{array}{c}\text { Mean } \\
\text { Differen }\end{array}$ & $\begin{array}{c}\text { Std. } \\
\text { Error } \\
\text { Differen }\end{array}$ & $\begin{array}{r}95 \% \mathrm{Co} \\
\text { Interva } \\
\text { Diffe }\end{array}$ & $\begin{array}{l}\text { fidence } \\
\text { of the } \\
\text { ence }\end{array}$ \\
\hline & & $\mathrm{F}$ & Sig. & $\mathrm{t}$ & Df & tailed) & ce & ce & Lower & Upper \\
\hline $\begin{array}{l}\text { Hasil } \\
\text { Belajar } \\
\text { Siswa }\end{array}$ & $\begin{array}{l}\text { Equal } \\
\text { variances } \\
\text { assumed }\end{array}$ & .387 & .538 & 8.736 & 33 & .000 & 13.013 & 1.490 & 9.982 & 16.044 \\
\hline & $\begin{array}{l}\text { Equal } \\
\text { variances not } \\
\text { assumed }\end{array}$ & & & 8.708 & $\begin{array}{r}32.10 \\
9\end{array}$ & .000 & 13.013 & 1.494 & 9.970 & 16.057 \\
\hline
\end{tabular}

Berdasarkan hasil output di atas, karena data yang diperoleh sudah homogen maka yang dilihat adalah Equal Variances Assumed diperoleh nilai Sig. (2-tailed) 0,000 < 0,05 maka dapat disimpulkan bahwa ada perbedaan yang nyata rata-rata hasil belajar siswa dengan menggunakan model pembelajaran kooperatif tipe Think Pair Share dan model pembelajaran konvensional.

Perbedaan rata-rata (mean) hasil belajar siswa pada kelas eksperimen dan kelas kontrol dapat dilihat pada tabel Group Statistic sebagai berikut:

Tabel 8. Hasil Output Test Statistic

\begin{tabular}{|l|lr|r|r|r}
\hline \multicolumn{7}{l}{ Group Statistics } \\
\hline & Kelas & $\mathrm{N}$ & Mean & Std. Deviation & Std. Error Mean \\
\hline \multirow{2}{*}{ Hasil Belajar Siswa } & Post-Test Kelas & 18 & 90.78 & 4.166 & .982 \\
& Eksperimen & & & & \\
\cline { 2 - 6 } & Post-Test Kelas Kontrol & 17 & 77.76 & 4.644 & 1.126 \\
\hline
\end{tabular}

Berdasarkan hasil output data diatas dapat diketahui rata-rata nilai post test kelas eksperimen yaitu 90,78 sedangkan pada kelas kontrol rata-rata nilai post test 77,76. Dengan demikian model pembelajaran kooperatif tipe Think Pair Share berpengaruh terhadap hasil belajar siswa kelas IV sekolah dasar pada tema 3 subtema 2 pembelajaran 1.

Dari pembahasan diatas, dijelaskan bahwa penggunaan model Think Pair Share dapat mempengaruhi hasil belajar siswa ditunjukkan dengan adanya peningkatan aktivitas dan hasil belajar siswa, ketertarikan 
1044 Pengaruh Model Think Pair Share Terhadap Hasil Belajar Siswa Sekolah Dasar - Laylatus Sholichah, Ery Rahmawati, Galuh Kartika Dewi

DOI: https://doi.org/10.31004/basicedu.v6i1.2079

belajar dengan berkelompok, mengajak siswa agar dapat mandiri, mengasah kecerdasan otak, berani berpendapat, lebih menyenangkan, siswa tidak mudah bosan. Hal ini sejalan dengan pendapat Sadipun (2020) model ini mengutamakan siswa untuk berperan aktif bersama teman satu kelompoknya melalui diskusi dan pemecahan masalah. Siswa berbagi ide pemecahan masalah dengan teman kelompoknya. Keadaan ini membuat siswa berpartisipasi lebih aktif dalam proses pembelajaran, yang nantinya mempengaruhi hasil belajar yang diperoleh setelah seseorang melakukan kegiatan belajar mengajar. Menurut Assidhiq (2019) bahwa anak sekolah dasar memiliki karakteristik senang bermain, senang bergerak, dan anak senang bekerja dalam kelompok. Oleh karena itu, setiap proses pembelajaran perlu diterapkan model pembelajaran yang sesuai untuk meningkatkan hasil belajar.

Hasil belajar siswa akan dipengaruhi oleh model pembelajaran di kelas yang digunakan oleh guru. Penggunaan model Think Pair Share dinilai dapat membuat siswa lebih aktif dan mandiri, memiliki jiwa sosial yang lebih tinggi dengan teman, serta berdampak pada peningkatan hasil belajar dan aktivitas belajar siswa (Huda, 2013). Penerapan mode Think Pair Share juga bermanfaat bagi guru, karena selain sebagai fasilitator pembelajaran, guru juga dapat memahami karakteristik belajar siswa. Berdasarkan uraian hasil data penelitian dapat diketahui bahwa model Think Pair Share memberikan dampak terhadap hasil dan aktivitas belajar siswa, serta dinilai lebih efektif merangsang semangat belajar siswa.

\section{KESIMPULAN}

Berdasarkan penelitian yang telah dilakukan, perolehan skor pada pengamatan aktivitas belajar siswa dari seluruh aspek yang dinilai memperoleh total skor 663 dengan persentase $92 \%$. Dengan jumlah persentase 92\% maka penggunaan model Think Pair Share memperoleh kriteria sangat baik. Dapat disimpulkan bahwa penggunaan model Think Pair Share membuat siswa menjadi lebih aktif dalam kegiatan pembelajaran serta berpartisipasi aktif dalam kegiatan diskusi. Pengamatan aktivitas belajar siswa hanya dilakukan pada kelas eksperimen.

Adapun hasil belajar siswa pada kelas kontrol memperoleh rata-rata nilai 77,76 dan dikelas eksperimen memperoleh rata-rata nilai post test 90,78 . Uji hipotesis yang digunakan dalam penelitian ini yaitu uji paired sampel t-test dan memperoleh hasil bahwa nilai Sig. (2-tailed) sebesar 0,000 $<0,05$. Sedangkan hasil uji hipotesis menggunakan independent sampel t-test menunjukkan bahwa data yang diperoleh sudah homogen maka yang dilihat adalah Equal Variances Assumed diperoleh nilai Sig. (2-tailed) 0,000 < 0,05. Hal ini menunjukkan bahwa ada pengaruh penggunaan model Think Pair Share terhadap hasil belajar siswa kelas IV sekolah dasar. Hal ini dibuktikan dengan meningkatnya hasil post test pada kelas eksperimen.

\section{UCAPAN TERIMA KASIH}

Ucapan terima kasih peneliti persembahkan kepada Allah SWT, kedua orang tua peneliti, dosen-dosen yang telah membimbing peneliti dari awal hingga selesai, dan teman-teman yang telah memberikan support kepada peneliti.

\section{DAFTAR PUSTAKA}

Assidhiq, Akmal, Alviani Saridevita, D. (2019). Tulisan Bersama Tentang Desain Pembelajaran Sd. Cv. Jejak.

Dewi, G. K. (2017). Pengembangan Perangkat Pembelajaran Contextual Teaching And Learning Dengan Media Mind Mapping Untuk Meningkatkan Hasil Belajar Siswa Pada Subtema Lingkungan Tempat Tinggalku Kelas Iv Sekolah Dasar. Jurnal Persada: Kajian Ilmu Pendidikan Dasar, 1(1), 9. 
1045 Pengaruh Model Think Pair Share Terhadap Hasil Belajar Siswa Sekolah Dasar - Laylatus Sholichah, Ery Rahmawati, Galuh Kartika Dewi

DOI: https://doi.org/10.31004/basicedu.v6i1.2079

Https://Repository.Stkippgri-Sidoarjo.Ac.Id/99/1/14.Pdf

Faizah, Z., Hanief, M., \& Dina, L. N. A. B. (2019). Profesionalisme Guru Dalam Meningkatkan Mutu Pendidikan Di Madarsah Ibtidaiyah Tahfidz Al-Asyhar Malang. Jurnal Pendidikan Madrasah Ibtidaiyah, 1(3), 134-140. Http://Riset.Unisma.Ac.Id/Index.Php/Jpmi/Article/View/3234/2886

Giantara, Febri, Astuti, A. (2020). Kemampuan Guru Matematika Mempertahankan Substansi Materi Melalui Proses Pembelajaran Online. Jurnal Cendekia : Jurnal Pendidikan Matematika, 04(02), 787-796.

Huda, M. (2013). Model-Model Pengajaran Dan Pembelajaran. Pustaka Pelajar.

Kirom, A. (2017). Peran Guru Dan Peserta Didik Dalam Proses Pembelajaran Berbasis Multikultural. Al Murabbi, 3(1), 74-75. Http://Jurnal.Yudharta.Ac.Id/V2/Index.Php/Pai/Article/View/893

Lazwardi, D. (2017). Manajemen Kurikulum Sebagai Pengembangan Tujuan Pendidikan. Al-Idarah: Jurnal Kependidikan Islam, 7(1), 99-112.

Lubis, M. A. Dan N. A. (2020). Pembelajaran Tematik Sd/Mi. Kencana.

Mundelsee, L., \& Jurkowski, S. (2021). Think And Pair Before Share : Effects Of Collaboration On Students $\begin{array}{lllll} & \text { Learning And Individual Differences, } & \text { 88(May }\end{array}$ Https://Doi.Org/10.1016/J.Lindif.2021.102015

Nabila. (2021). Tujuan Pendidikan Islam. Jurnal Pendidikan Indonesia, 2, 867-875.

Perdana, R., \& Suswandari, M. (2021). Literasi Numerasi Dalam Pembelajaran Tematik Siswa Kelas Atas Sekolah Dasar. Absis: Mathematics Education Journal, $3(1), \quad 9$. Https://Doi.Org/10.32585/Absis.V3i1.1385

Purwasih, S. M. (2020). Pemanfaatan Dakota Dalam Meningkatkan Hasil Belajar Matematika Pada Materi Fpb Dan Kpk. Jurnal Pendidikan Matematika, 11(1), 126. Https://Doi.Org/10.36709/Jpm.V11i1.10087

Rahmawati, E., \& Dewi, G. K. (2020). Penerapan Media Pembelajaran Peta Tiga Dimensi Melalui Pembelajaran Tutor Sebaya Untuk Meningkatkan Hasil Belajar Ips Pada Siswa Kelas Iv Sdn Banjaran Kecamatan Driyorejo Kabupaten Gresik. Jurnal Ilmiah Mandala Education, 6, 11. Https://Doi.Org/Http://Dx.Doi.Org/10.36312/Jime.V6i2.1340

Ramli, M. (2015). Hakikat Pendidik Dan Peserta Didik. Tarbiyah Islamiyah, 5(1), 61-85. Https://Jurnal.UinAntasari.Ac.Id/Index.Php/Tiftk/Article/View/1825

Sadipun, B. (2020). Penerapan Model Pembelajaran Kooperatif Tipe Think Pair Share Untuk Meningkatkan Prestasi Belajar Ips Siswa Kelas V Sdi Ende 14. Inteligensi: Jurnal Ilmu Pendidikan, 3(1), 11-16. Https://Doi.Org/10.33366/Ilg.V3i1.1461

Shoimin, A. (2017). 68 Model Pembelajaran Inovatif Dalam Kurikulum 2013. Ar-Ruzz Media.

Sugiarto, T. (2020). Contextual Teaching And Learning (Tcl) - Tingkatkan Hasil Belajar Peserta Didik. Cv. Mine.

Sugiyono. (2018). Metode Penelitian Pendidikan. Alfabeta.

Tari, E., \& Hutapea, R. H. (2020). Peran Guru Dalam Pengembangan Peserta Didik Di Era Digital. Kharisma: Jurnal Ilmiah Teologi, 1(1), 1-13. Https://Doi.Org/10.54553/Kharisma.V1i1.1

Trianto. (2014). Model Pembelajaran Terpadu. Pt. Bumi Aksara. 